\title{
When is Shuttle Diplomacy Worth the Commute? Information Sharing through Mediation*
}

\author{
Mark Fey ${ }^{\dagger}$ \\ Kristopher W. Ramsay \\ Work in Progress \\ Comments Welcome
}

January 2010

\begin{abstract}
We study the conflict mediation problem, sometimes called "shuttle diplomacy," when the mediator acts as a go-between and must gather information from the disputants. In the context of a general model of information mediation, we show that the incentive that disputants have to lie to the mediator undoes any advantage that might be gained by adding communication with a third party. In fact, our main result shows that any equilibrium outcome that is achievable through mediation is also achievable as an equilibrium outcome of a game with unmediated pre-play communication. This is true even when the mediator is allowed to have arbitrary preferences or biases. We then test our empirical prediction on dispute management efforts between 1937 and 1985. The analysis supports the hypothesis that information mediation has no effect in environments where the mediator has no independent source of information.
\end{abstract}

\footnotetext{
*Earlier versions of this paper were presented at the Columbia University International Politics Seminar and the 2009 American Political Science Association Meetings. We thank the participants for helpful comments. We also thank Matthew Gentkow, Hein Goemans, Pierce O'Reilly, and Larry Rothenberg for stimulating discussions.

†Department of Political Science, University of Rochester. email: mark.fey@rochester.edu

${ }_{\ddagger}^{\ddagger}$ Department of Politics, Princeton University, email: kramsay@Princeton.edu
} 


\section{Introduction}

Adversaries in international conflict often involve third parties to help them reach agreements. Although these efforts are not always successful, we know that mediation efforts are a recurrent and potentially important feature of international conflict. For example, Wilkenfeld, Young, Asal \& Quinn (2003) report that 30\% of crises between 1918 and 1996 were mediated at some point by a third party. As a consequence of the frequency with which mediation occurs, there has been significant interest in identifying the mechanisms that cause mediation success and failure. But even with the extensive work on the subject, there remains little consensus on the important question of how and when mediation will change the trajectory of a conflict.

Given the general interest in, and importance of, mediation in many conflicts, it is widely recognized that the act of mediation can take a variety of forms. One form of mediation that has received considerable attention is what Touval \& Zartman (1985) call facilitationcommunication meditation, or what Savun (2008) calls an information provision strategy. In these instances mediators work to facilitate the transfer of information between parties, with the underlying hypothesis that the mediator "serves as a channel of communication as contact breaks down between the parties in dispute. For example, the mediator may act as a go-between to carry information, proposals, or concessions back and forth between the conflicting parties" (Kleiboer 1996). Mediator intervention can also be procedural, such as when the mediator acts as an agenda setter (Camiña \& Porteiro 2009) or is the exclusive source of settlement proposals, like in arbitration. Finally, the most powerful form of intervention is directive mediation, in which a mediator acts as an enforcer of agreements (Goltsman, Hörner, Pavlov \& Squintani 2009) or provides selective incentives with respect to settlements - often depending on the credible threat of punishment (Favretto 2009) 1

We will focus on the first form of meditation and refer to it as information mediation. We do so for a number of reasons, some practical, some theoretical. First, information mediation is the most commonly observed form of mediation (Bercovitch \& Houston 2000). Presumably this is because the other, more intrusive, forms of mediation require a potential mediator to have significant capabilities to control the form of the interaction and to make credible threats of reward or punishment. In many cases, there may be only one or two third parties with the requisite international power to effectively implement these more direct strategies. Second, there is an ongoing debate in the scholarly literature about the role of information

\footnotetext{
${ }^{1}$ In game theoretic terms we can think of information mediation as adding a third player to an interaction to facilitate communication, procedural mediation as allowing the third party to manipulate the agenda, or the "game form," but not countries' payoffs over outcomes, and direct mediation as allowing the third party to change the game form and the preferences of the players by directly affecting payoffs.
} 
mediation and the conditions under which it can be effective. While it is clear, for example, how threats of punishment or reward can act to resolve disputes, it is less obvious how the provision of information can induce peace. In short, we focus on information mediation because it is both more easily supplied and potentially more subtle in its workings.

To date, a significant proportion of the theoretical work on mediators and mediation has focused on the kind of information mediation we study (Beber 2008, Kydd 2003, Kydd 2006, Rauchhaus 2006, Smith \& Stam 2003). Information mediation in its most simple form has two components. First, there is the mediator's acquisition of conflict-relevant information. Second, there is the problem of credibly communicating this relevant information to the parties in conflict. The existing literature almost exclusively focuses on the second problem, ignoring the first. These models assume that mediators are endowed with some independent knowledge of the private information of the disputants - knowledge that the disputants themselves do not possess. In some instances this is reasonable. If the mediator can gather information independently about some objective factor relevant to the decision to settle, then the problem of credible information transmission is of primary importance. A classic example of such a mediation event is the Gates Mission during the 1990 Indo-Pakisanti crisis. As Hagerty (1995) notes, in meetings with Pakistani and Indian leaders Robert Gates shared information taken from U.S. intelligence and war gaming that provided convincing evidence about the short and long term consequences of war. Hagerty writes "... the gist of the message to both sides was that war would be to neither side's advantage" (Hagerty 1995, p.101). Viewed as a bargaining game, we can understand this case as one in which the additional independent information that Gates supplied reduced the uncertainty of the two sides to a point at which an agreement was possible.

However, in some instances it is unreasonable to assume that a mediator can acquire significant independent knowledge about the private information of the disputants that the disputants themselves cannot acquire. ${ }^{2}$ As Beardsley (2008) puts it, "few intermediaries will have superior intelligence than the combatants themselves and also be willing to share such sensitive intelligence for another state's use." More commonly, this knowledge is a product of communication between the mediator and the disputants. Indeed, the common image of "shuttle diplomacy" involves the intermediary meeting with each side in turn and relying on these discussions to progress towards a solution. Additionally, the nature of the private information of the disputants can be such that it is impossible to gather significant independent knowledge relevant to the conflict. For example, if the uncertainty of the disputants

\footnotetext{
${ }^{2}$ The requirement that the information be something that the disputants themselves cannot acquire is important. It rules out commonly available sources of information such as news media reports and internet sources. Such information is available to all sides and thus is not independent knowledge of the mediator.
} 
concerns their level of resolve, their ideological commitment, or their personal preferences, it is hard to imagine how a mediator could acquire independent knowledge of these factors. This kind of information can only be gained by having the players willingly tell the mediator, and as Regan \& Aydin (2006) point out, acquiring and sharing of this privately valued information is generally understood to be an important part of the mediation process. As they put it:

Mediation facilitates the transfer of information quite efficiently. An outside mediator serves as the conduit for information, ideas, and possible concessions that [disputing] parties would not possibly convey without a third-party intermediary. ... Absent an outside intervention, the information held by the warring parties is at best asymmetrical, and neither side has a unilateral incentive to honestly convey its military capabilities, expectations of victory or defeat, or the value of a settlement that it would accept for the fear of exploitation by its adversary. Third parties can therefore influence the value of a settlement by transmitting information on the preferences of adversaries ...(741)

Thus, as noted by Rauchhaus (2006) our understanding of mediation "... would certainty benefit from endogenizing the process by which information is gained."

We fill this gap in existing theories of mediation by analyze both components of the information mediation problem simultaneously, focusing on the standard circumstance where decision-makers are uncertainty about their opponent's costs of fighting, resolve, or the value of the prize. That is, we consider a mediator who must both acquire information from the countries in the conflict and then find a way to credibly use that information to influence the outcome of the crisis. We allow our mediators to have any bias or preferences-including being a disinterested third party - and allow the interaction between the mediator and the countries to be private, public, or some mixture of the two. What we find is that in this environment there is a fundamental tension between these two components of information mediation: a mediator who can credibly reveal information to the parties will not be able to acquire this information from them. This is true because when the mediator asks the parties to reveal their private information, the same incentives that disputants have to lie to their opponents also exist when talking to the mediator. This incentive to misrepresent to the mediator then blocks any meaningful mediation. On the other hand, if the preferences of the mediator prevent her from credibly revealing information, the two sides have no reason to lie to the mediator because this revelation will not hurt them in bargaining. So, while it is possible to satisfy one component of the information mediation problem at a time, either truthful revelation by the disputants or credible communication by the mediator, it is 
impossible to find any mediator, of any stripe, or any set of mediation rules (i.e., any game form) that satisfy both conditions simultaneously. Thus, when the mediator's information comes from communication with the disputants, there is no way for the mediator to reach an outcome that the disputants could not have reached without the aid of the mediator. Using a mediator to intervene and facilitate communication, contrary to the above conjecture of Regan \& Aydin (2006), cannot overcome the incentive to misrepresent information that is present in unmediated communication.

To put our theoretical result in context, it is useful to compare it to other recent theoretical models of mediation, such as Kydd (2003), Kydd (2006), and Rauchhaus (2006). Each of these three papers provide sufficient conditions for when a mediator can credibly and truthfully reveal information in a way that changes the distribution of crisis outcomes. For example, Kydd (2003) shows that in a setting with uncertainty about disputants' costs of war, if a mediator has enough, but not too much, bias and also has an exogenous source of private information about the disputants' costs, then the mediator's actions can change a country's beliefs about its opponent's type and, therefore, that country's bargaining behavior. Similarly, Rauchhaus (2006) shows - with different definitions of bias and impartiality - that if a mediator is either strictly biased toward the challenger or some conditions on prior beliefs and preferences hold and the mediator is impartial, and also the mediator has an exogenous source of private information about the disputants' costs, then a mediator's actions can change the outcome of the crisis bargaining game for the better. Both of these results provide interesting and important insights into how the characteristics of the crisis environment affect the prospects of meaningful mediation. One might ask, however, which, if any, of these conditions - bias, impartiality, and exogenous sources of information - are essential for mediation to be effective? Unfortunately, the models of Kydd (2003) and Rauchhaus (2006) do not provide an answer to this question, as they provide sufficient conditions for meaningful mediation. In this paper, however, we show that one of these conditions, namely the existence of an exogenous source of information, is in fact a necessary condition for effective mediation. Specifically, we show that in any crisis bargaining situation where settlements are voluntary - in the sense that every disputant can always achieve at least their war payoff-a mediator's actions can affect crisis outcomes only if the mediator has an exogenous source of information regarding the disputants' types $3^{3}$

\footnotetext{
${ }^{3}$ Technically we prove the contrapositive of this claim, if the mediator has no exogenous source of information regarding the disputants' types, then the actions of the mediator cannot increase (or decrease) the set of equilibrium distributions over outcomes reached with cheap talk alone. Our necessary result is also slightly broader in two ways than the results in the literature. First, our necessary condition applies to a broad class of bargaining games, of which the standard models are examples, and we not only compare the set of outcomes with mediation to bargaining outcomes, but rather to the bargaining outcomes that can be achieved when in a game from our class is extended to allow for arbitrary pre-play cheap talk. This exten-
} 
While the difference between sufficient and necessary conditions may seem only the concern of theorists, they also have starkly different implications for the empirical world. The existing sufficiency results show that effective mediation is potentially observable, while our necessity result shows that such observations must involve mediators with independent knowledge, as in the Gates Mission during the 1990 Indo-Pakisanti crisis. The testable prediction of our result is therefore that while information mediation will sometimes be observed as successful, disaggregating the cases of information mediation should reveal that the successful cases occur only with knowledgable mediators while mediators without independent knowledge are generally unsuccessful.

To demonstrate the intuition of our theoretical result, we first look at an example in a simple take-it-or-leave-it bargaining environment. We then show that the incentive to misrepresent to a mediator exists in a very large class of bargaining games of which many classical crisis games are examples. The scope conditions of our theorem include all possible conflict bargaining games with voluntary agreements and all possible forms of pre-play communication with privately valued private information. We also consider all possible forms of mediation and all possible preferences of the mediator. Our main result is that, in all cases, any equilibrium outcome that is achievable through mediation is also achievable as an equilibrium outcome of a game with unmediated pre-play communication. Thus, if the mediator's only source of information is what the disputants choose to reveal, the incentive that disputants have to lie to the mediator undoes any advantage that might be gained by adding private communication with a third party. In many settings, then, considering both components of information mediation gives a very different picture than previous work that only considers the credible revelation of information. When we consider the incentives of parties to reveal information to the mediator as well as the incentives of the mediator to use this information, we see that the mediator can do no better than what is possible through direct pre-bargaining cheap talk communication by the two parties 4

Though the focus of this paper is on the theoretical foundations for information mediation in conflict, the intuition and results apply equally to information based arguments for the value of international institutions and organizations. Following a similar argument as in the mediation literature, neoliberal institutionalists claim an important function of international institutions is their ability to reduce uncertainty and solve asymmetric information problems

sion is trivial in the Kydd and Rauchhaus models as the cheap talk extensions produce no new equilibrium distributions over outcomes.

${ }^{4}$ The game theory papers most closely related to ours are those that study cheap talk in double auctions. The construction of the pre-play cheap talk game is similar to that found in Farrell \& Gibbons (1989), though the message space is larger. In a similar way, it is related to Satterthwaite \& Williams (1989). The closest theory paper to ours is Matthews \& Postlewaite (1989), which gives a similar result for two-person sealed-bid double auctions. 
that cannot be "rectified by communication" (Keohane 1984, p.93). In some instances the information required to overcome these obstacles to cooperation can be obtained by monitoring state behavior or employing experts (Koremenos, Lipson \& Snidal 2001). In other instances, however, countries must self-report key economic or political statistics or provide unverifiable assessments of their compliance with an international agreement or an aspect of international law. In either of the latter cases, the concerns motivating this study of mediation apply equally well to international institutions. Thus our results are relevant for more than those interested in mediation, they speak to the potential for international institutions, in general, to help countries capture gains from cooperation in the face of uncertainty.

As stark as our theoretical conclusion may be, its significance for those interested in the empirical study of mediation ultimately rests on an empirical question: does the record on mediation support our theoretical implication? The existing literature is mixed. On one side, there is a significant body of work on mediation (e.g., Bercovitch (1986), Beardsley (2008), Savun (2008)) that consistently finds that facilitation-communication mediation (what we call information mediation) is the least effective type of mediation for settling disputes. Furthermore, Savun (2008) shows with a clearer measure of a mediator's outside information that mediators are effective to the extent that they have access to high quality outside information. In a closely related literature, however, mediation is shown to be positively associated with the peaceful settlement and de-escalation of international disputes. Prominent among these works is Dixon (1996), which analyzes the SHERFACS data on 688 interstate disputes and finds that mediation is effective at promoting peaceful settlements. Therefore, in this paper we reanalyze the SHERFACS data to test our theoretical prediction. In order to do so, we unpack Dixon's mediation variable to differentiate between information mediation and other types of mediation. This allows us to more precisely evaluate the situations where our result applies. Our reanalysis supports our claim that information mediation, in the absence of exogenous sources of information, has no significant effect on the likelihood of ending a dispute.

The rest of the paper proceeds as follows. In the next section we consider a simple take-itor-leave-it bargaining game as in Fearon (1995). Much of the intuition for our general result can be found through this example. The following section describes a class of bargaining games that form the core of the crisis bargaining problem. Our main result follows, where we show that any equilibrium outcome that can be achieved from the mediation extensions of any crisis bargaining game can also be obtained as an equilibrium outcomes of a single-stage cheap talk extension of the same crisis bargaining game. After we present our result, and discuss how it relates to the other theoretical literature on mediation, we present our empirical 
analysis. Our prediction, that information mediation has no significant independent effect on ending disputes is shown to be consistent with the empirical record surrounding third party intervention in disputes. The final section concludes.

\section{An Example}

To make the intuition for our general result clear, we begin by considering a simplified version of a standard model of crisis bargaining, due to Fearon (1995). In this example, two states are involved in a dispute which may lead to war. We conceptualize the conflict as occurring over a divisible item of unit size, such as an area of territory or an allocation of resources. This model involves a take-it-or-leave-it offer by country 1, which country 2 either accepts or rejects. If an offer $(x, 1-x)$ is accepted by country 2 , then countries 1 and 2 receive payoffs of $x$ and $1-x$, respectively. If country 2 rejects the offer, then war ensues and each country $i$ receives its war payoff. We normalize the utility of countries to be 1 for victory in war and 0 for defeat, and we suppose there is a cost $c_{i}>0$ for country $i$ fighting a war. We let the probability that country 1 wins the war be $p \in(0,1)$. In this example, we suppose that the value of $c_{1}=.1$ is common knowledge but the value of $c_{2}$ is private information. That is, country 2 knows the true value of $c_{2}$, but country 1 only knows that $c_{2}$ is equally likely to be .1 or .5 .

In order to solve for the perfect Bayesian equilibrium of this game, we begin by noting that country 2 will accept any offer such that $1-x \geq 1-p-c_{2}$, which simplifies to $x \leq p+c_{2}$. Thus, country 1 should either offer $x=p+.1$, which will be accepted by both types of country 2 , or offer $x=p+.5$, which will only be accepted by the high cost type of country 2 . In the former case, the payoff to country 1 is just $p+.1$ and in the latter case, the low cost type of country 2 will reject the offer, which results in war. Therefore the expected utility of offering $x=p+.5$ is

$$
\frac{1}{2}(p-.1)+\frac{1}{2}(p+.5)=p+.2
$$

This is the optimal offer for country 1 even though it carries with it a $50 \%$ chance of war. The logic behind this result is known as the risk-reward tradeoff in the literature.

Building on this result, Fearon (1995) shows that allowing players to communicate before bargaining does not reduce the risk of war. The reason such "cheap talk" has no effect is that there is a insurmountable incentive for the high cost type to misrepresent its cost and act as though it were a low cost type. The only equilibrium in such a model involves the two types of country 2 "pooling" and acting the same way in the communication phase. 
To see this in the context of our example, suppose there is a set of possible messages $M$ available to country 2. After country 2 chooses one of these messages to send to country 1 , the game proceeds as described above. In particular, the payoffs to the two countries are not affected by the choice of message - the message is "cheap talk." Can there be a (pure strategy) equilibrium in which the two types of country 2 choose different messages? To answer this question, suppose that the high cost type of country 2 sends message $m_{h}$ and the low cost type of country 2 sends message $m_{l} \neq m_{h}$. 5 To see how country 1 will respond to this, note that because the two types of country 2 are sending different signals, country 1 can correctly infer the type of its opponent based on the message sent. That is, after receiving $m_{l}$, country 1 knows for sure its opponent is the low cost type, and after receiving $m_{h}$, country 1 knows for sure its opponent is the high cost type. Given this, it is clear that country 1 will offer $x=p+.1$ after receiving the message $m_{l}$ and it will offer $x=p+.5$ after receiving the message $m_{h}$. We now show that this cannot be an equilibrium. To see this, note that for the high cost type of country 2 , sending the equilibrium message $m_{h}$, which leads to an offer of $x=p+.5$, yields a payoff of $1-x=1-p-.5$. On the other hand, if the high cost type deviates and send the message $m_{l}$, then this leads to an offer of $x=p+.1$, which country 2 will accept, yielding a payoff of $1-p-.1$. As this is clearly a profitable deviation, there cannot be an equilibrium in which the two types send different messages. Thus, this example illustrates the importance of the incentive to misrepresent private information and how this incentive prevents meaningful cheap talk in bargaining. Moreover, as there cannot be meaningful cheap talk in equilibrium, country 1 will face the same decision problem as it does in the game without cheap talk and therefore will make the same choice as it does in the game without cheap talk. The eventual outcome will not change. That is, in the game with cheap talk, the unique equilibrium is still that country 1 offers $x=p+.5$, which leads to war with the low cost type of country 2.

Having seen that the incentive to misrepresent private information precludes meaningful cheap talk in this example, we now consider how this incentive to misrepresent affects mediated solutions to conflict. To illustrate this, we introduce a third player into our model - the mediator. We do not restrict the preferences of the mediator in any way; she could be neutral, or biased towards one of the two countries, or prefer to avoid conflict, or any other preference. We also do not restrict the exact nature of the mediation process; the mediator can gather information from one or both sides involved in the conflict, the mediator can go back and forth to the sides an arbitrary number of times, and the mediator can decide to pass on all, some, or none of the information she acquires at each stage. Whatever the form of the mediation process, after it concludes the original game is played. That is, country 1

\footnotetext{
${ }^{5}$ Here we focus on pure strategies, but the result continues to hold when mixed strategies are allowed.
} 
makes an offer $(x, 1-x)$ which is either accepted or rejected by country 2 . To focus on the case of informational mediation, we suppose that the mediator's only source of information is the two sides involved in the dispute - the mediator cannot independently access the private information of country $2 \sqrt[6]{6}$ We also suppose that the mediator cannot change the structure or payoffs of the game through, for example, threats of punishment or reward.

We now turn to the analysis of this game with mediation. Fix a (pure strategy) equilibrium to this game.7 This equilibrium specifies the choices for the two types of country 2 in the mediation stage, as well as the corresponding behavior for the mediator and country 1 during mediation. It also specifies the settlement offer $x$ made by country 1 after any possible mediation outcome. As there are two possible types of country 2, in this pure strategy equilibrium there are at most two different outcomes of the mediation stage. We use the notation $r_{l}$ to denote the equilibrium mediation outcome when country 2 is the low cost type and $r_{h}$ to denote the equilibrium mediation outcome when country 2 is the high cost type. There are two cases to consider. First, consider the case that $r_{h} \neq r_{l}$. In this case, the two types of country 2 behave differently in their interaction with the mediator and suppose the mediator finds it in her interest to pass on this information to country 1 . Country 1 will respond to these different outcomes just as it does in the cheap talk setting above. That is, after observing $r_{h}$, country 1 knows for sure that it is facing the high cost type and it will offer $x=p+.5$. Likewise, after observing $r_{l}$, country 1 knows it faces the low cost type and will offer $x=p+.1$. But now, as in the cheap talk setting, this gives the high cost type an incentive to mimic the behavior of the low cost type in the mediation phase, resulting in $r_{l}$ and the more favorable offer $x=p+.1$. Thus this case cannot be an equilibrium. Here, the same incentive to misrepresent private information precludes meaningful mediation. The second case to consider is that $r_{h}=r_{l}$. This case can arise when either the two types act the same way in mediation or when they act differently, but the mediator chooses not to pass on this information to country 1 . Given that $r_{h}=r_{l}$, the beliefs of country 1 do not change - country 1 still thinks it is equally likely it is facing the low cost and high cost type of country 2. As the information of country 1 is exactly the same as in the original game, the equilibrium in this case must also be exactly the same. Thus, country 1 offers $x=p+.5$, which leads to war with the low cost type of country 2 . We conclude that, regardless of the

\footnotetext{
${ }^{6}$ In this example, if the mediator has access to the private information of country 2 , the mediator can insure peace. In particular, if the mediator is unbiased and has no preference for war or peace, truthful revelation is credible. Thus, country 1 learns the cost of country 2 and is able to make the appropriate offer, which will be accepted. Thus, war does not occur. More generally, if the mediator receives an independent noisy signal about the cost of country 2 and prefers peace to war, then the mediator must be biased in order to be credible (Kydd 2003).

${ }^{7}$ Here again, we focus on pure strategies for reasons of tractability. As before, the same results hold if we permit mixed strategies.
} 
preference of the mediator or the form of the mediation process, the equilibrium outcome is unchanged from the original game.

To summarize, in this model, permitting cheap talk does not change the outcome of the bargaining process and neither does the addition of a mediator. This simple model also illustrates the tension between the mediator being able to acquire information and being able to credibly transmit this information. When the mediator will credibly transmit information $\left(r_{h} \neq r_{l}\right)$, country 2 is unwilling to reveal any useful information. Likewise, country 2 is willing to reveal information if it is sure this information cannot be credibly transmitted $\left(r_{h}=r_{l}\right)$. Information mediation can be meaningful only when a country is willing to reveal information and the mediator can credibly convey this information. In this example, one of these two parts is possible, but not both.

\section{Mediation and Crisis Bargaining: A General Result}

\subsection{The General Framework}

In the previous section, we presented a simple example to illustrate our argument. But we must be careful in drawing general conclusions from this example. For instance, there are bargaining problems in which cheap talk does affect the outcome (Farrell \& Gibbons 1989, Smith 1998, Sartori 2002, Ramsay 2004, Kurizaki 2007). Perhaps in more complicated bargaining situations there are things that the disputants are willing to tell the mediator that they are not willing to tell each other. More broadly, we should be careful about making general claims based on special cases (Fey \& Ramsay 2009). Therefore, in this section we establish a general result that shows that the lessons of this example carry over to a broad class of crisis bargaining games.

We first provide a general framework for modeling international crisis bargaining. Specifically, we consider situations where two countries involved in a dispute can attempt to avoid war through some bargaining process. In order to be as general as possible, we describe (abstractly) this process by a "game form" $G$ which is composed of a set of actions for each country, $A_{1}$ and $A_{2}$, and an outcome function $g\left(a_{1}, a_{2}\right)$ for $a_{1} \in A_{1}$ and $a_{2} \in A_{2} .^{8}$ It is worth emphasizing that this game form can be anything from a simple strategic form game to an arbitrarily complicated extensive form. We denote a pair of actions $\left(a_{1}, a_{2}\right)$ by $a \in A=A_{1} \times A_{2}$. So, a game form defines the actions available to the disputants (e.g., what negotiation tactic to use, etc.) and how those actions interact to determine outcomes.

\footnotetext{
${ }^{8}$ For simplicity, we assume that each $A_{i}$ is finite. Our results continue to hold in the infinite case, although there are additional technical details to deal with.
} 
A crisis bargaining game is a game form in which the final outcome is either a peaceful settlement or an impasse that leads to war. As before, if $p_{i}$ and $c_{i}$ denote the probability that country $i$ wins a war and the cost to war to country $i$, respectively, then the payoff of war to country $i$ is just $p_{i}-c_{i}$.

We allow more general specifications of uncertainty by supposing that each country is (potentially) uncertain about the other's cost for fighting. Formally, we suppose that country $i$ 's cost of war, $c_{i} \in\left[0, \bar{c}_{i}\right]=C_{i}$, is private information, which is distributed according to a cumulative distribution function $F_{i}\left(c_{i}\right) !^{9}$ We denote a pair of types by $\left(c_{1}, c_{2}\right)=c$. In order to be as general as possible, we make no assumption about the form of $F_{i}$. It could be continuous or discrete, or even degenerate. Because countries can condition their choice of action on their private information, we define a strategy for country $i$ by a function $s_{i}: C_{i} \rightarrow A_{i}$. The set of all possible strategies for state $i$ is $S_{i}$ and we let $\left(s_{1}, s_{2}\right)=s \in S=S_{1} \times S_{2}$. The equilibrium concept we employ is Bayesian-Nash equilibrium. In particular, a strategy profile $s^{*}$ is a Bayesian-Nash equilibrium if each type of each player is playing a best response to the strategies used by the other players.

Given the anarchic nature of the international system, we identify one feature that must be present in any game form that purports to be a model of crisis bargaining, namely that a country cannot be forced to accept a settlement that makes it worse off than by going to war. Formally, we require that in every crisis bargaining game, for each $i=1,2$ there exists an action $\tilde{a}_{i} \in A_{i}$ such that $u_{i}\left(\tilde{a}_{i}, a_{j}, c_{i}\right) \geq p_{i}-c_{i}$ for all $a_{j} \in A_{j}$ and all $c_{i} \in C_{i}$. We refer to this condition as voluntary agreements. Different models in the literature express this feature in different ways. In the take-it-or-leave-it bargaining model discussed above, country 2 has a literal choice between accepting the offer and going to war. That is, $\tilde{a_{2}}$ is rejecting the offer of country 1 . On the other hand, for country 1 in this model $\tilde{a_{1}}$ can be any demand $x \geq p-c_{1}$, because country 1 will receive a payoff of either $x$ if country 2 accepts or $p-c_{1}$ if country 2 rejects the demand. Likewise, in the "crisis subgame" of Bueno de Mesquita \& Lalman (1992) and in the related games of Kim \& Bueno de Mesquita (1995), Fearon (1994), and Smith (1995), both countries have a strategy that results in either war or capitulation by their opponent. Such a strategy satisfies the requirement for $\tilde{a}_{i}$ given above.

\footnotetext{
${ }^{9}$ It is important to note our construction is one where uncertainty is about the countries' private values of war. The standard in the formal crisis bargaining literature has been to focus on "cost" uncertainty, which is such a privately valued aspect of the war payoff. Consistent with our substantive description of the problem, the incomplete information is about unverifiable aspects of countries' preferences. In related work, Horner, Morelli \& Squintani (2009) consider the related problem of mediation with private information about interdependent payoff parameters, i.e. the probability of winning, and find different results. Smith \& Stam (2003) also have uncertainty over interdependent valued parameters, but also have exogenous information sources for the mediator.
} 


\subsection{Main result}

Our main result is that the outcomes of mediated communication are the same as the outcomes of direct communication between the disputants when there is uncertainty about costs. Thus, we augment the underlying bargaining process $G$ in two ways. We first consider adding bilateral communication ("cheap talk") with no mediator and then consider adding a third-party mediator to this communication phase.

In the first case, we construct the cheap talk extension of $G$, denoted by $G^{c}$, by allowing the two countries to send messages back and forth before beginning the bargaining process. We allow this communication to take a general form in that there can be several rounds of communication and in each round countries can send messages simultaneously or in sequence. Our construction follows that of Forges (1990) and Ben-Porath (2003). Formally, we suppose that each side has a (finite) set of possible messages $M_{i}$. After the countries learn their types, they exchange messages back and forth according to the extensive form $G^{c}$. The structure of $G^{c}$ is arbitrary; messages can be sent over a number of stages and can be simultaneous or sequential in each stage. In the last stage of $G^{c}$, the two sides choose their actions $\left(a_{1}, a_{2}\right)$ in the crisis bargaining game $G$. The messages in $G^{c}$ are "cheap talk" because they do not affect payoffs directly. That is, payoffs in $G^{c}$ are determined solely by the choice of action in the final stage $G$. So for all messages $m_{1}$ and $m_{2}$, all actions $a_{1}$ and $a_{2}$, and all types $c_{i}$,

$$
u_{i}^{c}\left(m_{1}, m_{2}, a_{1}, a_{2}, c_{i}\right)=u_{i}\left(a_{1}, a_{2}, c_{i}\right)
$$

where $u_{i}^{c}$ is country $i$ 's payoff in the cheap talk extension $G^{c}$. A full strategy for country $i$ in $G^{c}$ indicates which messages to send as a function of its type and which actions to choose from $A_{i}$ in the final stage, as a function of its type and the messages sent and received in $G^{c}$. Because messages are cheap talk, we refer to an outcome generated by a full strategy in $G^{c}$ as a mapping from types into actions $\left(a_{1}, a_{2}\right)$ in $G$ generated by the given full strategy.

Alternatively, we can construct the mediation extension of $G$, denoted by $G^{m}$, by introducing a third-party mediator who can communicate with both parties and offer recommendations to the two parties before the bargaining process begins. Again, we allow this mediation to be quite general in that the communication can occur over several rounds and can involve multiple exchanges of messages between the mediator and the two countries. We are also general about whether these messages are public or private. That is, we permit each message of each actor to be either private (i.e., received by only one other actor) or public (i.e., received by both other actors). Most importantly, we impose no restriction on the motivation of the mediator. The mediator can be completely neutral or biased toward 
one or the other country or biased toward peace or have any other motivation 10

The formal construction of $G^{m}$ is similar to that of $G^{c}$ described above, with the exception that $G^{m}$ is a three player game, with the players being the two disputants countries and the mediator ${ }^{11}$ Each of the three actors has a (finite) set of possible messages $M_{i}$. The two countries and the mediator exchange messages according to the extensive form $G^{m}$. Once again, the structure of $G^{m}$ is arbitrary, with a number of stages each involving simultaneous or sequential messages. In $G^{m}$, however, each message can be either public or private. Public messages are received by all actors, while private messages are received by only one of the other actors ${ }^{12}$ As with $G^{c}$, the messages in $G^{m}$ are cheap talk, so that for all messages $m_{1}$, $m_{2}$, and $m_{3}$, all actions $a_{1}$ and $a_{2}$, and all types $c_{i}$,

$$
u_{i}^{c}\left(m_{1}, m_{2}, m_{3}, a_{1}, a_{2}, c_{i}\right)=u_{i}\left(a_{1}, a_{2}, c_{i}\right),
$$

for countries $i=1,2$. The payoff of the mediator is an arbitrary function of the actions chosen by the two countries in the crisis bargaining game $G$. That is, for the mediator,

$$
u_{3}^{c}\left(m_{1}, m_{2}, m_{3}, a_{1}, a_{2},\right)=u_{3}\left(a_{1}, a_{2}\right) .
$$

Also, a full strategy for country $i$ is a mapping from types into messages and actions. A full strategy for the mediator is a messaging strategy indicating which messages to send in response to the messages that the mediator receives. As before, an outcome of a full strategy profile in $G^{m}$ is a mapping from types into actions in $G$. Formally, this is a mapping from $C_{1} \times C_{2}$ into $A_{1} \times A_{2}$.

Although we allow the preferences of the mediator to be arbitrary, we do make two assumptions about any mediation extension of $G$. First, we assume that the mediator has no private information of their own, cannot directly observe the private information of either side, and cannot verify any claims the the two sides makes about their private information. In other words, the only knowledge that the mediator can obtain comes from the exchange of messages between the mediator and the two countries. As messages can be private, a mediation extension can involve disputants choosing to send private messages to the mediator and the mediator deciding which information to pass on privately to the two sides. This is specified by the structure of $G^{m}$ and determines the messaging strategy available to the

\footnotetext{
${ }^{10}$ This is an important point of departure from that work of Forges (1990) and Ben-Porath (2003). Those papers include a mediator, but only as a mechanistic coordination device - a theoretical construct to aid in the analysis. In our paper, the mediator is a fully rational player with strategies and preferences in $G^{m}$.

${ }^{11}$ When necessary, we denote the mediator by player $i=3$.

${ }^{12}$ To conserve notation, we represent each message by three elements of $M_{i}$ : one for the public version of the message, one for the private version sent to actor $j \neq i$, and one for the private version sent to the actor $k \neq j$.
} 
mediator. But the mediator in $G^{m}$ can only respond to messages sent by the disputants, it does not have access to the private information involved. Second, we assume that the mediator does not have the power to change the game form $G$. That is, we suppose that the mediator can engage in arbitrary communication with the two sides and make public or private recommendations about what actions each country should take in the play of $G$, but the mediator cannot directly impose, prevent, or change the payoff of any outcome in $G$. Thus, the extensive form of $G^{m}$ involves the play of $G$ after every possible messaging history.

Finally, in order to make the argument as clear as possible, we strengthen the voluntary agreements condition described above in the following manner. In order to insure that in both cheap talk extensions and mediation extensions of $G$ any peaceful agreement must be voluntary, we suppose that after $G$ has been played and a settlement has be reached, each country always has the option of rejecting the proposed settlement if it thinks it will be better off by using force. Formally, we suppose that in any cheap talk extension or mediation extension of $G$, every terminal node of $G$ is followed by a final stage in which the two countries simultaneously choose whether to accept or reject the settlement. The settlement is adopted if both sides accept it and otherwise the outcome is war. We refer to this final stage as the "ratification stage" of the cheap talk or mediation extension of $G$. Put simply, there is no way to force a country to accept an agreement that makes it worse off than it would be by going to war.

Note that with these assumptions, a strategy for play in a cheap talk extension of $G$ must specify the choices of countries players in the messaging stage, how these messages affect the play of $G$, and the decisions of the countries in the ratification stage after $G$. Likewise, for a mediation extension of $G$, we must specify the messages of the countries, the preferences and actions available to the third-party mediator as well as the strategy of the mediator in response to the messages of the countries, the effect of all of these messages on the play of $G$, and finally the ratification decisions of the countries for every terminal node in $G$.

We are now ready to state our general result. This result states every equilibrium outcome of every cheap talk extension of $G$ is an equilibrium outcome of some mediation extension of $G$ and, conversely, every equilibrium outcome of every mediation extension of $G$ is an equilibrium outcome of some cheap talk extension of $G$. In other words, the sets of equilibrium outcomes for $G^{c}$ and $G^{m}$ are the same and no outcome reached by mediation is unreachable without it.

Theorem 1 Let $G$ be an arbitrary crisis bargaining game form with voluntary agreements. The set of equilibrium outcomes of $G^{c}$ is equal to the set of equilibrium outcomes of $G^{m}$. 
Proof: To prove the first direction, pick any equilibrium of any cheap talk extension of $G$. Choose a mediator with arbitrary preferences for the mediation extension of $G$. In this mediation extension, let each side play a strategy in which they send public messages corresponding to the messages sent in the equilibrium of the cheap talk extension and ignore any messages from the mediator. Also, let the mediator send no messages. Finally, let the two sides play the same in $G$ as in the equilibrium of the cheap talk extension. Because the messaging strategy for the two sides is the same as in the equilibrium of $G^{c}$ and the mediator does not send messages, it is optimal to play this same messaging strategy in the mediation phase and play the same way in $G$. The mediator is willing to send no messages because any message she sends will be ignored. In this way, the mediation extension achieves the exact same communication as the cheap talk extension. Finally, because any equilibrium of $G^{c}$ must give each country at least their war payoff, the same outcome in $G^{m}$ will be agreed to at the ratification stage. Therefore, this outcome is an equilibrium outcome of some mediation extension of $G$.

The reverse direction is more difficult. Pick any equilibrium of any mediation extension of $G$. Such an equilibrium must specify a strategy for how each country sends messages in the communication stage, how the mediator reacts to these messages and responds with her own messages, and how these messages influence the choice of actions by the countries when they proceed to play the underlying game $G$. By the definition of equilibrium, each of these strategies must be optimal, given the play of others. In a manner similar to the "general revelation principle" (Myerson 1982, Forges 1986, Myerson 1991), we can view the mediated communication phase of the equilibrium of $G^{m}$ as a mapping from the type space $C_{1} \times C_{2}$ into a recommended action profile $a \in A$. Because the mediator could be playing a mixed strategy in this equilibrium of $G^{m}$, this mapping is a probability distribution $\mu(a \mid c)$ which gives the probability that the mediator will recommend action $a_{i}$ to country $i$ given types $c$. We refer to this mapping as a mediation mechanism for $G^{m}$.

Our goal is to specify a cheap talk extension $G^{c}$ and construct an equilibrium of $G^{c}$ with the same distribution of outcomes as $\mu(a \mid c)$. To begin, we define $G^{c}$ to be a cheap talk extension of $G$ in which each country makes a simultaneous announcement and then $G$ is played.

Before we construct the desired equilibrium of $G^{c}$, we need the following preliminary definitions. First, fix an arbitrary ordering of the elements of $A$, so that $A=\left\{a^{1}, a^{2}, \ldots, a^{|A|}\right\}$. Given a probability distribution $\mu(a \mid c)$, we view this a discrete density on the ordering of the elements of $A$ and form the corresponding cumulative distribution function $\chi(a \mid c)$ on this ordering. Second, define a fractional sum function $\phi:[0,1]^{2} \rightarrow[0,1]$ as follows. For every $r_{1}, r_{2} \in[0,1]$, let $\phi\left(r_{1}, r_{2}\right)$ be the fractional part of the sum $r_{1}+r_{2}$. That is, 
$\phi\left(r_{1}, r_{2}\right)=r_{1}+r_{2}-\left\lfloor r_{1}+r_{2}\right\rfloor$, where $\lfloor x\rfloor$ greatest integer less than or equal to $x$. Importantly for our purposes, if $r_{1}$ and $r_{2}$ are independent random variables and one of them is uniformly distributed on $[0,1]$, then $\phi\left(r_{1}, r_{2}\right)$ is uniformly distributed on $[0,1]$.

We now define the strategies for the desired equilibrium. In the communication phase of $G^{c}$, country $i$ announces its true type, $c_{i}$, as well as a number $r_{i}$ that is independently drawn from a uniform distribution on $[0,1]$. Given the type announcements $c_{1}$ and $c_{2}$ and the two announced values $r_{1}$ and $r_{2}$, let $a^{*}=\chi^{-1}\left(\phi\left(r_{1}, r_{2}\right) \mid c\right)$. In the game $G$, country $i$ plays $a_{i}^{*}$. In the ratification phase, if the action profile played in $G$ was $a^{*}$, then both countries play the action that they would have played in ratification phase of $G^{m}$ after $a^{*}$. If the action profile played in $G$ was not $a^{*}$, then both countries reject the end result and choose war. Clearly, on the equilibrium path of play, the distribution of outcomes in this equilibrium of $G^{c}$ is identical to the distribution of outcomes of the equilibrium of $G^{m}$.

In order to show that these strategies form an equilibrium of $G^{c}$, we consider each stage in turn, working backwards. In the ratification stage, if the action profile played in $G$ was $a^{*}$ as required, then playing the actions played by the equilibrium of $G^{m}$ is clearly optimal. On the other hand, if a different action profile was played, then it is an equilibrium for both countries to reject because if country $j$ is rejecting, then war occurs whether or not country $i$ rejects. Given these portions of the strategies are optimal, consider the play in $G$. If country $i$ chooses an action other than $a_{i}^{*}$, then the eventual outcome is war. If country $i$ chooses the prescribed action $a_{i}^{*}$ then the eventual outcome is an equilibrium outcome of $G^{m}$. But since every equilibrium outcome of $G^{m}$ gives both countries at least their war payoff, deviating to some other action is not profitable. Finally, consider the messaging stage in $G^{c}$. Recall that if $r_{j}$ is chosen uniformly, then $\phi\left(r_{1}, r_{2}\right)$ is uniformly distributed regardless of how $r_{i}$ is chosen. Therefore, country $i$ has no incentive to choose $r_{i}$ in a different manner. To show that announcing your true type is optimal, we appeal to the general revelation principle again. Specifically, because the mediation mechanism $\mu$ is generated by an equilibrium of $G^{m}$ and is therefore optimal and the strategies defined in $G^{c}$ generate the same same distribution of outcomes as $\mu(a)$, it is an equilibrium for both countries to truthfully reveal their types and play accordingly. This proves the theorem.

So what have we shown? This theorem establishes that when the mediator must gather information from the two disputants, the set of outcomes achievable through a third party mediator is exactly the same as the set of outcomes achievable through direct cheap talk by the two sides. The proof is constructive - it lays out the equilibrium strategies necessary in a cheap talk game to achieve the same outcome as in a mediation game.

While some, like Kydd (2003), Moravcsik (1999) and Beardsley (2008), have suggested that such a result may be true, it is worthwhile to note that our theorem is much different 
from the existing literature on cheap talk and mediation. For example, it is known that with two players, there are game forms in which mediated communication can achieve outcomes that are not attainable by cheap talk messaging (Forges 1990, Krishna 2007). But these counterexamples involve the play of correlated equilibrium in games with coordination opportunities. Our result, on the other hand, deals with crisis bargaining games in which there is a direct conflict of interest. Another striking difference between our result and the theoretical literature on mediation in games of incomplete information is that we permit the mediator to be an additional player in the game, with arbitrary preferences. In the existing literature (Forges 1990, Ben-Porath 2003, Gerardi 2004, Krishna 2007), mediated communication involves a non-strategic communication device that receives and transmits messages, but does not have preferences over outcomes. Again, our broader result is possible because we focus on crisis bargaining games with voluntary agreements and mediation games with a ratification phase.

\section{Theoretical Discussion}

A few aspects of our theory and results call for further discussion. As we note above, we agree with Kydd (2003) that “... [there are] two questions that any theory of mediation as information provision must answer. First, how does the mediator get the information that she is to provide? Second, when can the mediator credibly communicate this information to the negotiating parties?" But unlike the existing formal literature on mediation, that focuses solely on the credible communication question with no regard to the issue of acquiring private information, we focus on situations where both problems exist simultaneously.

In some circumstances the assumption that the mediator has exogenous information is perfectly reasonable, and in those instances issues of credible communication dominate. For example, if uncertainty is about the probability of success in a violent conflict or about some commonly valued element of the prize-like how much oil is under a disputed territory-then third-party mediators can gather relevant information. In fact, the literature on mediation and third-party intervention explicitly considers such operations. These third party actions are ones where the outsider is tasked with "fact-finding" which can lead to proposals or arbitration. But for other aspects of the environment-in particular privately valued preference based uncertainty-such information can only be voluntarily revealed by the disputant who holds the preference. In such circumstance a mediator can act as a "go between" and offer proposal as to how to settle a disagreement, but the information they can gather is largely at the discretion of the parties 13

\footnotetext{
${ }^{13}$ One potentially interesting source of information for the mediator may be previous secret or private
} 
When the underlying uncertainty concerns the parties' levels of resolve, ideological commitments, or personal preferences the exogenous information assumption is more problematic. So while it is sometimes possible for mediators to gather data that is relevant to a dispute that the participants cannot gather, like satellite imagery or communication intercepts, these exogenous information assumptions will not apply if the key information driving the dispute is some subjective preference or hidden constraint faced by a disputing leader. The fundamental fact is that whatever these factors are can only be known to the members of the dispute and can only be learned by the mediator if the disputants are willing to honestly share this information.

As our example illustrates, the tension between the credibility of the mediator's recommendation and the incentive for parties to misrepresent their private information acts to inhibit meaningful mediation. It is easy to see how these issues play out in the existing models of mediation. Take Kydd's (2003) model of biased mediators for example. The main result of this paper is that if the mediator is endowed with independent knowledge and has the right amount of bias, then the mediator can pass on her information in a way that alters the trajectory of the conflict for the better. This new trajectory, moreover, is not one that could be reached through direct communication between the parties to the dispute. But suppose that instead of being endowed with separate information, the mediator must gather information from the disputants. Would the player with private information in this game ever reveal it willingly to such a mediator? The answer is no, because in Kydd's equilibrium, one side makes more generous offers when informed by the mediator that its opponent has low costs. Therefore, as in the example in Section 2, the high cost type has an incentive to lie to the mediator and claim that it has low costs. In this way, the gains from mediation that are present in Kydd's model with exogenously informed mediators vanish when the mediator must rely on information revealed by the disputants. Moreover, as Kydd points out in his model, when the bias of the mediator is outside of the specified range, it is impossible for the mediator to credibly reveal information. For example, when the mediator is neutral and simply prefers to avoid conflict, she "will face an insuperable incentive to lie. Lying will make peace more likely; telling the truth will make conflict more likely" (p. 606). In other words, the mediator will always want to claim that her information is that costs are low, even when she knows differently. But then, knowing this, the side with private information is willing to truthfully reveal it to the mediator - since the mediator cannot credibly reveal this information there is no risk in revealing it. Thus, we again see how the tension between the

interactions between the mediator and the disputants. It should be noted, however, that even this information is to a great extent controlled by the diplomatic strategy of the actors and can be subjected to the same set of incentives to misrepresent or mislead in expectation of future interactions. 
credibility of the mediator and the incentives to reveal information interact. If the mediator gathers her information from the two sides, then we have the following. The mediator can credibly communicate her information exactly when the uninformed player has an incentive to lie to the mediator, and this player is willing to tell the truth exactly when the mediator has an incentive to lie to the other side. Thus, as our general result tells us, the presence of the mediator provides no additional opportunities for settlement. Our general result also implies that these arguments are not unique to Kydd's model. Similar conclusions would hold in similar models like Rauchhaus (2006).

Importantly, our conclusion about the information mediation problem do not depend on the preferences or biases of the mediator. The mediator may prefer war to peace, peace to war, one participant over the other, or anything else. As the preceding discussion of Kydd's model emphasizes, the different levels of bias may interact with the incentives of the disputants to reveal information in different ways, but the overall outcome will be the same. Mediator bias that generates credibility leads to an incentive to misrepresent information to the mediator, while levels of bias that lead to the mediator misrepresenting her information permit truthful revelation of information to her. But whatever the mediator's bias is, the result is the same: nothing is gained through mediated communication when the mediator must both extract information and credibly communicate it.

As mentioned in the introduction, our theoretical result also complements the existing sufficiency results in the literature. While every result we are aware gives us a set of indicators that allow us to look for places where mediation can or should be affective, we prove a necessary condition that helps us identify what is essential for an information mediator to add value and change outcomes of a crisis. We show that in the standard theoretical setting, a mediator must have an exogenous source of information to make a difference. When joined with the results of Kydd $(2006,2003)$ and Rauchhaus (2006) we have that exogenous information is necessary, and with a few conditions on mediator preferences, sufficient for the possibility of successful mediation.

While not directly a theory of international institutions and organizations, our result also applies to these entities when they take on a mediation role. Thus our result speaks to widely held views on the role of international organizations in resolving disputes and achieving Pareto-improving outcomes through assistance in the bargaining process. As Keohane (1984) argues, international institutions can "reduce transaction costs" and promote cooperation by providing information in cases where asymmetries of information lead to bargaining failure. Theorem 1 shows that the informational role of institutions must be limited in such a functionalist argument. That is, institutions - like specially informed mediators - can influence bargaining outcomes with their actions as long as the institutional decision-makers 
preferences are consistent with credible sharing of what they know. But again, this only works if the institution has information not available to the participants. If the international organization must extract or collect private information from the parties with the aim of sharing some of it in order to facilitate an agreement, then the international organization faces the same problem as our mediator. This is not to say institutions cannot play other information sharing roles, such as monitoring a country's otherwise unobservable behavior. They just cannot solve the cheap talk problem for disputing countries simply by acting as a go between and a source of non-binding proposals.

\section{Analysis of Information Mediation in Disputes}

As noted in the introduction, to those interested in the empirical study of mediation the ultimate value of this result is its ability to explain the success or failure of mediation. With this in mind we turn to some empirical results in international relations that are consistent with the substance of our claim. We follow this discussion with a simple test of our own that, when taken together with the other findings, supports our theoretical claim.

Existing empirical studies of mediation evaluate the effectiveness of the three styles of mediation identified in the classical literature: communication-facilitation, procedural, and directive/manipulative. There are two fairly consistent findings in this literature that relate to our argument. First, in direct comparisons of the three styles when mediation occurs, the communication-facilitation style is found to be the least effective in resolving conflicts (Bercovitch 1986, Bercovitch \& Houston 1996, Bercovitch \& Houston 2000). Second, and more interesting from our perspective, several recent papers have shown that the communication-facilitation style is actually no better at resolving conflicts than unmediated communication (Quinn, Wilkenfeld, Smarick \& Asal 2006, Beardsley, Quinn, Biswas \& Wilkenfeld 2006, Quinn, Eralp, Wilkenfeld, Asal, McLauchlin \& Brecher 2009). For example, Quinn et al. (2009) state the "[p] ure facilitative mediation appears to add little benefit to the process of resolving violent, ethnic, intra-state crises. In fact, our results show that a pure facilitative approach to mediation is less likely to get parties to compromise than if they were left to their own devices." These papers offer support for our argument that communication mediation cannot achieve outcomes beyond those achievable by direct bilateral discussion.

Even stronger support can be found in recent empirical work by Savun (2008). Her article distinguishes itself from previous work on mediation by focusing on the kind of information that mediators possess. Building a measure of mediator information using the mediator's diplomatic representation in the disputants' territories, its trading relationships, and its institutionalized military alliance ties with the countries in conflict, Savun finds that mediators 
Table 1: Effect of Mediator Information Level

\begin{tabular}{ccccc} 
& \multicolumn{4}{c}{$\begin{array}{c}\text { Predicted Probability of } \\
\text { Mediation Involvement }\end{array}$} \\
\hline Information & None & Low & Medium & High \\
\hline & 0.006 & 0.053 & 0.231 & 0.559 \\
& \multicolumn{4}{c}{ Predicted Probability of } \\
& \multicolumn{4}{c}{ Mediation Success } \\
\hline Information & None & Low & Medium & High \\
\hline & 0.014 & 0.060 & 0.182 & 0.397 \\
& & Source: Savun & $(2008)$
\end{tabular}

with access to independent information from these sources are much more likely to successfully resolve conflicts. From her results, we can quantify the extent to which independent information affects the performance of third party mediation.

Savun estimates a selection model that both estimates whether mediation occurs and whether whether mediation is successful. We present a summary of her results in Table 1 . Specifically, Savun finds the predicted probability of mediation success for countries with high levels of information is twenty eight times greater (.397) than those with zero information (.014) and more than six times greater than those with low levels of information (.060). She finds an even bigger difference in the predicted probability of mediation occurrence as a function of the level of mediator information. Thus, Savun's evidence also provides empirical support for our claim that mediators without access to independent information are no more effective than direct negotiations at resolving disputes.

Finally, there is some interesting experimental evidence that supports our argument. Wilkenfeld et al. (2003) conducted a laboratory experiment on mediation. The scenario in the experiment was loosely based on the 1981 Ecuador/Peru border dispute. A total of 212 University of Maryland undergraduates participated in simulations. In each simulation, one student represented Ecuador and one student represented Peru. The two sides could communicate through a computer interface and, as a result of their negotiations, could reach outcomes varying from acceptance of the pre-crisis status quo to imposition of a cease fire to all-out war. There were three treatments considered; no mediation, information mediation, and directive mediation. Research assistants served as mediators and could interact with the two sides via the computer interface. In the information mediation treatment, the mediator could relay messages and act "as a sounding board" but could not affect the payoffs of the players. More importantly for our argument, in this treatment the mediator did not 
have access to the private information about payoffs that each side had available on its own computer screen. In the directive mediation treatment, the mediator had rewards and punishments available that the information mediator did not. Specifically, a directive mediator could alter the payoffs of the two sides in order to make agreement more palatable. Within the simulation, these effects were described as economic sanctions, foreign aid, and arms sales. Other elements of the simulation that affected payoffs included not just the eventual outcome but also the length and severity of the crisis.

Wilkenfeld et al. (2003) present a number of findings from their experiment. They investigate the effect of mediation on the likelihood of avoiding war, the overall payoff of the subjects, and the length of the crisis. While both mediation treatments were more likely to reach an agreement, the authors find that "only [directive] mediation has a positive effect on the level of benefits associated with crisis termination and on the duration of a crisis. Date from the Ecuador/Peru simulations indicate that only [directive] mediation meets the negotiator's expectations of leading them to a more beneficial outcome than they could have otherwise secured. On the other hand, [information mediation] may actually lower average benefits ..." (p. 297) This result is exactly what we would expect. Given that the information mediator in the simulation must rely on the two sides to reveal relevant information, our argument would imply that this treatment would be no better than the no mediator treatment. This is precisely the conclusion reached by the authors.

Although these studies offer impressive support for our theoretical prediction, there is other research, such as Dixon (1996), Rauchhaus (2006), and Frazier \& Dixon (2006), that finds that mediation can be effective at increasing the probability of settlement and deescalation of disputes. How does our theoretical argument square with these papers? The answer stems from the fact that our theoretical argument focuses on a particular kind of mediation, namely information mediation in which the mediator must rely on the two sides for its information, as unsuccessful. As we address in the introduction, there are sound theoretical reasons why other types of mediation could be successful. So the findings in these papers that certain broad categories of mediation are effective do not speak directly to our claim, as they do not focus on the specific type of mediation considered in this paper.

Therefore, we reanalyze the SHERFACS data, which forms the basis for these papers, by unpacking the mediation variable specified by Dixon (1996) to differentiate between information mediation and other types of mediation. In order to maintain comparability, we stick as close to possible to the empirical strategy of Dixon (1996) and Rauchhaus (2006). The few changes we make are driven by the need to better match our empirical model to our theoretical analysis. After making these simple changes, the resulting model finds that information mediation does not have a significant effect on settlement, while the other com- 
ponents of Dixon's definition of mediation have a positive effect on the likelihood of ending a disputes.

The SHERFACS dispute data contains observations on 688 crises between 1937 and 1984 Employing a typology developed by Skjelsbaek (1986), Dixon (1996) analyzes the effect of seven different types of third-party intervention on the escalation and settlement on disputes. These interventions included public appeals, communication facilitation (particularly through good offices), mediation, observation, political and military intervention, humanitarian aid, and adjudication by formal international bodies. One of the reasons the SHERFACS data has been used widely in the study of third party interventions is that it is specifically designed to evaluate conflict management interventions techniques, explicitly codes mediation attempts, and breaks crises into the various phases. Dixon argues that the most important characteristics of this data is that it disaggregates conflict situations into distinct phases that describes a crisis as a dynamic process. Each conflict is characterized by a series of phases that map the changes in degree of intensity of the dispute. The risk (or actual presence) of direct military hostilities is what marks the transition between phases. It is also worth noting that the SHERFACS data explicitly allows for complex trajectories of a conflict. Phases include the initiation of a dispute or conflict, conflicts where at least one party exhibits some intention to use military force, the use of military force, posthostilities environments where force is no longer being used, but the threat is still explicit, post-hostilitiy situations where there is little risk of a return to open military actions, and termination or settlement 15 This disaggregation by phases gives the analyst the ability to capture empirical variation in management practices within a crisis while still being sensitive to the context surrounding those practices (Dixon 1996, p.661).

\subsection{Dependent variables}

With a general understanding of the data to be used, the next issue to consider is the choice of dependent variable. Focusing on the 1683 observations where dispute outcomes were known at the time of completing data collection, Dixon (1996) analyzes two dependent variables, Escalation and Peaceful settlement. As it is crucial for our analysis, it is worth describing how these variables are constructed. As noted above, the SHERFCAS data sorts dispute phases into six categories. There are two pre-hostility phases (I and II), a phase where at least one side has used military force (III), two post-hostility phases (IV and V), and a

\footnotetext{
${ }^{14}$ Both Dixon (1996) and Sherman (1994) mention that they cover crises form 1945-1985, but there are crises in the data that begin before 1945, like the Chinese civil war (start date 1937), the First Peruvian Border War (1941), and the India-Pakistan Partition (1942). It is worth noting that the ICPSR data archive registers the correct incident dates in the description file (Sherman 2000).

${ }^{15}$ For a detailed description of this data see Sherman (1994).
} 
settlement phase (VI), which is the final phase commencing with a settlement or agreement resolving the underlying issues or causes of the dispute (Sherman 2000). An Escalation is then a movement to a phase "closer to" level three. Thus, an escalation can be a move from phase $\mathrm{V}$ to IV, a move from phase I to III, or any other movement to a situation with higher risk of military hostilities. Importantly, escalation can occur in both the pre- and post-hostility phases.

The second dependent variable considered by Dixon is called Peaceful settlement. The SHERFACS data records what type of settlement, if any, was reached in a given phase of each the 688 crises. While the data set itself is quite detailed, with 15 distinct types of settlement and another 21 combinations of empirically occurring phase transitions, it is difficult to decide which types of settlements to include in a settlement measure. Dixon (1996) indicates a Peaceful settlement if a phase concludes with some sort of agreement between parties. He does not distinguish between comprehensive and partial agreements, but does not count settlements imposed through military defeat or that occur with contemporaneous escalation. It turns out that such a rule, while clearly reasonable, includes as settlements disputes that dissipate under no action of either side, disputes that become subsumed in a larger conflict, and disputes subordinated to a new separate issue. Most importantly, these settlements need not end the dispute nor need they prevent future escalations.

For our purposes, however, neither of these two dependent variables is quite right. Our theoretical prediction does not speak to the probability of escalation within an unsettled dispute. Nor can we make any prediction about the likelihood that partial non-terminating agreements are reached during a crisis. Thus our model is not properly tested by using either Dixon's settlement or escalation variable. Fortunately, our theoretical claim does speak to an dependent variable very much like Dixon's Peaceful settlement, namely, the Dispute ends variable constructed by Rauchhaus (2006). The Dispute ends variable considers cases where a particular phase transitions to termination. The phase can end in its current active phase (I-V) or the phase may transition to a terminal settlement (phase VI), but partial agreements and actions that do not end a dispute are not counted as success under this condition. We make only the minor additional modification that a dispute is not, at least peacefully, ended if there is the elimination of one of the two parties.

\subsection{Measures of mediation}

As discussed above, in order to address our theoretical claim about information mediation we need to unpack the mediation variable used by Dixon (1996) to isolate the cases that it applies to. However, mediation is just one of seven different types of third-party interven- 
tions that Dixon considers. We begin our discussion by describing these categories and how they are operationalized by Dixon using the SHERFACS data. The first category, public appeals, registers whether or not a third party used public statements to pressure disputants to end their conflict. A second category, communication, marks all those instances by third parties to facilitate communication, but not interject themselves or offer any services to the disputants. Fact-finding and field observations are considered observation services and comprise a third type of intervention. The forth type of third party involvement, called intervention, records the physical presence of a managing agent, including peacekeeping missions, or any attempt at coercion, which includes embargoes, quarantines, or military assistance to either side. Dixon also includes humanitarian aid as a fifth category of intervention in his analysis, and adjudication as a specialized form of conflict management preformed solely by a small number of international judicial institutions. We leave each of these variables unchanged in our analysis.

The variable that we are most interested in is mediation. In Dixon (1996), this variable designates any type of third party intervention - including arbitration and conciliation - that involves the drafting and promotion of plans for conflict resolution. As coded in SHERFACS, this measure includes situations where third parties act as go-betweens, situations where they are adjudicators in binding arbitration, and situations where the third parties "cause negotiations to happen," which the dataset labels conciliation.16 As we have discussed, our theoretical claim applies only to a subset of such actions. Therefore, we will pull apart this variable, creating two new variables. The first, which we still call mediation consists only of the instances in which a third party acts as a go-between in negotiations. The remaining cases we include in a variable we call arbitration/conciliation. We also require one further refinement of our new mediation variable. Recall that our theoretical claim does not apply to all mediators that play an informational role, but only to those that do not have access to exogenous knowledge about the two sides and must extract the information preventing settlement from the actors. Our claim does not apply to mediators with independent knowledge of the dispute. In order to capture this distinction, we refine our mediation variable to be not just a third-party acting as a go-between, but also one who is a go-between in a crisis before any third party has participated in fact-finding, as specified in the SHERFACS data. We call this new variable information mediation. While admittedly a crude measure, it seems likely that if independent third party reports are available there is a good chance a mediator will have access to it. Thus we should not include such cases in our empirical test 17

\footnotetext{
${ }^{16}$ This definition of conciliation appears different from the standard definition of conciliation-a nonbinding variety of arbitration - but we follow the usage in the SHERFACS codebook here.

${ }^{17}$ If anything this measure is biased against us, as we are only excluding one kind of case in which the
} 
Finally, it is important to understand the distinction between the information mediation variable as we have just defined it and the communication variable. The latter variable is described in the SHERFACS data as covering the enunciation of issues and the provision of good offices ${ }^{18}$ Crucial for our purposes, this variable therefore describes situations which encourage bilateral communication, but which do not involve the third-party as an active participant. This matches our theoretical distinction between bilateral unmediated cheap talk and mediation. As we have shown, we would expect bilateral cheap talk, as measured by the communication variable, to (possibly) have an effect on the peaceful resolution of disputes, but our prediction is that information mediation as measured by our information mediation variable should have no further effect beyond what is achieved by bilateral cheap talk.

\subsection{Empirical results}

In order to maintain a close comparison with the existing literature, we will stick as close as possible to Dixon's (1996) specification of the statistical model. As discussed above, we will expand the on Dixon's (1996) analysis of third-party mediation by considering the Dispute ends variable both because of well formulated previous arguments for it by Rauchhaus (2006) and its appropriateness for testing our theoretical claim. We will also investigate the effect of unpacking the mediation variable into the information mediation variable and the arbitration-conciliation variable.

Our empirical results are given in Table 2. In the first column we replicate the results of the logistic regression in Dixon (1996). Our estimated coefficients are almost exactly the same as reported in that paper ${ }^{19}$ We see that communication, mediation, and adjudication have positive and significant effects on the Peaceful settlement dependent variable. But as discussed above, this variable includes both partial settlements and disputes that do not end, and may escalate. Therefore, in the second column we keep Dixon's logit specification and change the dependent variable to our version of Rauchhaus's (2006) Dispute ends. This specification produces significant results only for communication and the two phase characteristics. Mediation and adjudication become insignificant in this model and the estimated effects are substantially smaller than in the first column. For the next column, we run a slightly different statistical model in order to better capture the variation in the data. Though not considered in the original article, it is likely that various sources of unobserved

mediator has external information, namely previous fact-finding. Other kinds of informed mediators will still be included in our measure which should make it harder to confirm our prediction.

${ }^{18}$ Good offices is considered here to be the provision of of a meeting place or support materials only.

${ }^{19}$ The minor differences in the coefficients can be attributed to the fact we are using updated SHERFACS data in our estimation. 
Table 2: Logistic estimates of the effect of management attempts on ending disputes.

\begin{tabular}{|c|c|c|c|c|}
\hline \multirow[b]{2}{*}{ Model: } & \multirow{2}{*}{$\begin{array}{c}\text { Settle } \\
\text { logit }\end{array}$} & \multicolumn{3}{|c|}{ Dispute End } \\
\hline & & logit & clogit & clogit \\
\hline \multirow{2}{*}{ Public Appeals } & -.22 & .16 & .36 & .37 \\
\hline & $(.20)$ & $(.24)$ & $(.35)$ & $(.35)$ \\
\hline \multirow[t]{2}{*}{ Communication } & $47^{* *}$ & $.67^{* *}$ & $1.09^{* *}$ & $1.05^{* *}$ \\
\hline & $(.20)$ & $(.23)$ & $(.40)$ & $(.39)$ \\
\hline \multirow[t]{2}{*}{ Mediation } & $.69^{* *}$ & .11 & $.51^{*}$ & - \\
\hline & $(.18)$ & $(.20)$ & $(.28)$ & \\
\hline \multirow[t]{2}{*}{ Information mediation } & - & - & - & .39 \\
\hline & & & & $(.46)$ \\
\hline \multirow[t]{2}{*}{ Arbitration-Conciliation } & - & - & - & $.68^{* *}$ \\
\hline & & & & $(.33)$ \\
\hline \multirow[t]{2}{*}{ Observation } & -.22 & .12 & .46 & .54 \\
\hline & $(.21)$ & $(.25)$ & $(.42)$ & $(.43)$ \\
\hline \multirow{2}{*}{ Intervention } & -.04 & .51 & $1.16^{* *}$ & $1.19^{* *}$ \\
\hline & $(.28)$ & $(.33)$ & $(.50)$ & $(.49)$ \\
\hline \multirow[t]{2}{*}{ Humanitarian aid } & .32 & .10 & $-1.08^{*}$ & $-1.23^{* *}$ \\
\hline & $(.40)$ & $(.33)$ & $(.55)$ & $(.56)$ \\
\hline \multirow[t]{2}{*}{ Adjucation } & $.73^{*}$ & .19 & -1.88 & -1.86 \\
\hline & $(.32)$ & $(.33)$ & $(1.34)$ & $(.1 .30)$ \\
\hline \multirow[t]{2}{*}{ Crisis Phase } & $-1.75^{* *}$ & $-2.37^{* *}$ & $-1.89 * *$ & $-1.88^{* *}$ \\
\hline & $(.14)$ & $(.13)$ & $(.19)$ & $(.19)$ \\
\hline \multirow[t]{2}{*}{ Hostility Phase } & $-1.23^{* *}$ & $-4.63^{* *}$ & $-4.03^{* *}$ & $-4.05^{* *}$ \\
\hline & $(.17)$ & $(.36)$ & $(.43)$ & $(.44)$ \\
\hline \multirow[t]{2}{*}{ Constant } & -.08 & $.94^{* *}$ & - & - \\
\hline & $(.07)$ & $(.08)$ & & \\
\hline Chi-square (df) & $232(9)$ & $437(10)$ & $129(9)$ & $131(10)$ \\
\hline$R^{2}$ & .11 & .29 & .33 & .33 \\
\hline$n$ & 1683 & 1683 & 1008 & 1008 \\
\hline
\end{tabular}

Entries are logistic and conditional logistic regression estimates; standard errors (clustered on disputes in columns 2-4) are in parentheses. As in Dixon (1996), * denotes $p \leq 5$ and $* *$ denotes $p \leq .01$ for the one-tailed test. Constants are not identified in conditional logit models.

heterogeneity exists within a dispute, and ideally we would also want to estimate the effect of an intervention using the within-dispute variation in our statistical model. Therefore, we report in column three the conditional logit (i.e., "logit fixed-effects") coefficients using the same specification and dependent variable in the second column. Here we see that a number of disputes had no within-dispute variation on intervention and therefore the number of 
exploited observations drops to 1008. In terms of coefficients, we see that communication, mediation, and intervention have significant association with an increased likelihood of a dispute ending.

Finally, we consider the effect of unpacking the mediation variable into the two variables information mediation and arbitration-conciliation. In column four, we estimate a model that differs from column three only by replacing the mediation variable with these two new variables. As can be seen, the coefficients on the other variables are essentially unchanged, as one would expect, but the significant and positive coefficient on mediation in column three is replaced by an insignificant coefficient on information mediation and a significant and positive coefficient on arbitration-conciliation. The results show that the effect of mediation estimated in column three is really the effect of arbitration and conciliation and not information mediation. This agrees exactly with our argument that while bilateral cheap talk, as measured by the communication variable, and procedural, directive and exogenously informed mediation, as measured by the arbitration-conciliation variable, can be effective, information mediation without independent knowledge should not be effective. Therefore, we would argue that this result combined with the results of Bercovitch \& Houston (1996), Quinn et al. (2009), Savun (2008), and others mentioned above forms a compelling body of evidence that our theoretical insight into the general difficulty of information mediators helping countries end their disputes is empirically plausible.

\section{Conclusion}

International mediation is an intriguing facet of international conflict. In many cases, the mediator relies on the disputing parties to reveal private information that can be used to resolve the conflict. However, the disputing parties have an incentive to misrepresent their information in the hopes of obtaining better settlement terms. We have shown that this incentive to misrepresent private information prevents the mediator from achieving any agreement that the two parties could not achieve by direct negotiations between themselves. In this way, the results of existing formal models of mediation depend crucially on the assumption that the mediator can acquire information about the conflict that the two sides cannot acquire themselves.

This is not to say that models in which mediators are endowed with independent private information are wrong; indeed in some circumstances third parties may have the technological means to generate such information. However, it must be understood that the results of these models depend in an essential way on the mediator's access to such information. Any successful explanation of the informational role of mediation must therefore include 
identifying the source of this external information for the mediator. But when the underlying uncertainty at issue is something that is inherently inaccessible, such as individual preferences or the innate resolve of a leader, it is not clear how a mediator could acquire independent knowledge other than what the leader chooses to reveal.

One way to view our argument is that for mediation to be successful, it must do something more than simply serve as a channel for communication between the disputants. For example, the mediator could be setting the agenda, as in procedural mediation, or offering inducements or punishments, as in directive mediation. But we would also suggest that there may be reasons that the disputants choose to use information mediation, even when the mediator does not possess private information. For some countries, such as Iran and the United States or North Korea and the United States, direct talks are not physically possible, because the countries do not host embassies of the other side. In other cases, domestic politics may make direct talks problematic. For example, at the time of the Oslo Accords the Israeli government faced strong opposition on the subject of direct negotiation with the Palestinians. Thus the Norwegians were able to provide cover for secret talks that led to agreement on the Accords. In these cases, mediation makes direct talks possible. Of course, other explanations for the use of mediation are possible - we have not attempted to explain all possible cases of mediation, rather we have explored the limitations of mediation as communication and information provision.

Finally, a body of existing empirical evidence and our new empirical results both suggest that our theoretical claim has real world bite. Not only have direct tests of information mediation in the laboratory and in empirical studies shown that mediators with low levels of private information have little effect on crisis outcomes, our reanalysis of well known work in the literature on third-party intervention shows that we can 1) separate out empirically the effective of information mediation and other forms of mediation and 2) conclude that much of the effect of mediation one finds in these studies comes from types of mediation, not information mediation. Specifically, we see that positive results continue to hold for some mediation acts, such as adjudication and conciliation, but that information mediation has not effect. So while we admit that any single such piece of evidence would not be sufficient to believe the empirical implication of our theoretical claim, collectively they imply our hypothesis should not be ignored. 


\section{References}

Beardsley, Kyle. 2008. "Agreement without Peace? International Mediation and Time Inconsistency Problems." American Journal of Political Science 52(4):723-740.

Beardsley, Kyle, David Quinn, Bidisha Biswas \& Jonathan Wilkenfeld. 2006. "Mediation style and crisis outcomes." Journal of Conflict Resolution 50(1):58-86.

Beber, Bernd. 2008. "A Formal Theory of the Initiation and Implementation of Mediation in Wars.".

Ben-Porath, Elchanan. 2003. "Cheap talk in games with incomplete information." Journal of Economic Theory 108(1):45-71.

Bercovitch, Jacob. 1986. "International mediation: A study of the incidence, strategies and conditions of successful outcomes." Cooperation and Conflict 21(3):155-168.

Bercovitch, Jacob \& Allison Houston. 1996. The study of international mediation: Theoretical issues and empirical evidence. In Resolving international conflicts: The theory and practice of mediation, ed. Jacob Bercovitch. Lynne Rienner Publishers pp. 11-35.

Bercovitch, Jacob \& Allison Houston. 2000. "Why do they do it like this? An analysis of the factors influencing mediation behavior in international conflicts." Journal of Conflict Resolution 44(2):170-202.

Bueno de Mesquita, Bruce \& David Lalman. 1992. War and Reason: Domestic and International Imperative. New Haven, CT: Yale University Press.

Camiña, Ester \& Nicolás Porteiro. 2009. "The role of mediation in peacemaking and peacekeeping negotiations." European Economic Review 53(1):73-92.

Dixon, William J. 1996. "Third-party Techniques for Preventing Conflict Escalation and Promoting Peaceful Settlements." International Organization 50(3):653-681.

Farrell, J. \& R. Gibbons. 1989. "Cheap Talk Can Matter in Bargaining." Journal of Economic Theory 48(1):221-237.

Favretto, Katja. 2009. "Should Peacemakers Take Sides? Major Power Mediation, Coercion, and Bias." American Political Science Review 103(2):248-263.

Fearon, James D. 1994. "Signaling versus the Balance of Power and Interests: An Empirical Test of a Crisis Bargaining Model." Journal of Conflict Resolution 38(2):236-269. 
Fearon, James D. 1995. "Rationalist Explanations for War." International Organization 49(3):379-414.

Fey, Mark \& Kristopher W. Ramsay. 2009. "Uncertainty and Incentives in Crisis Bargaining: Game-Free Analysis of International Conflict." Mimeo, University of Rochester .

Forges, Francoise. 1986. "An Approach to Communication Equilibria." Econometrica 54(6):1375-85.

Forges, Francoise. 1990. "Universal mechanisms.” Econometrica 58(6):1341-1364.

Frazier, Darrick V. \& William J. Dixon. 2006. "Third-Party Intermediaries and Negotiated Settlements, 1945-200.” International Interactions 32(4):385-408.

Gerardi, Dino. 2004. "Unmediated communication in games with complete and incomplete information." Journal of Economic Theory 114(1):104-131.

Goltsman, Maria, Johannes Hörner, Gregory Pavlov \& Francesco Squintani. 2009. "Mediation, arbitration and negotiation." Journal of Economic Theory 144(4):1397-1420.

Hagerty, Devin T. 1995. "Nuclear Deterrence in South Asia: The 1990 Indo-Pakistani Crisis." International Security 20(3):79-114.

Horner, Johannes, Massimo Morelli \& Francesco Squintani. 2009. "Mediation and Peace." Mimeo, Columbia University .

Keohane, Robert. 1984. After Hegemony. Princeton, NJ: Princeton University Press.

Kim, Woosang \& Bruce Bueno de Mesquita. 1995. "How Perceptions Influence the Risk of War." International Studies Quarterly 39(1):51-65.

Kleiboer, Marieke. 1996. "Understanding success and failure of international mediation." Journal of Conflict Resolution 40(2):360-389.

Koremenos, Barbara, Charles Lipson \& Duncan Snidal. 2001. "The Rational Design of International Institutions." International Organization 55(4):761-799.

Krishna, R. Vijay. 2007. "Communication in games of incomplete information: Two players." Journal of Economic Theory 132(1):584-592.

Kurizaki, Shuhei. 2007. "Efficient Secrecy: Public versus Private Threats in Crisis Diplomacy." American Political Science Review 101(3):543-558. 
Kydd, Andrew. 2003. "Which Side Are You On? Bias, Credibility, and Mediation." American Journal of Political Science 47(4):597-611.

Kydd, Andrew. 2006. "When Can Mediators Build Trust?" American Political Science Review 100(03):449-462.

Matthews, Steven A. \& Andrew Postlewaite. 1989. "Pre-play communication in two-person sealed-bid double auctions." Journal of Economic Theory 48(1):238-263.

Moravcsik, Andrew. 1999. "A new statecraft? Supranational entrepreneurs and international cooperation." International Organization 53(02):267-306.

Myerson, Roger B. 1982. "Optimal Coordination Mechanisms in Generalized Principal-Agent Problems." Journal of Mathematical Economics 10(1):67-81.

Myerson, Roger B. 1991. Game Theory: Analysis of Conflict. Boston, USA: Harvard University Press.

Quinn, David, Jonathan Wilkenfeld, Kathleen Smarick \& Victor Asal. 2006. "Power Play: Mediation in Symmetric and Asymmetric International Crises." International Interactions 32(4):441-470.

Quinn, David, Pelin Eralp, Jonathan Wilkenfeld, Victor Asal, Theodore McLauchlin \& Michael Brecher. 2009. "Overcoming Barriers to Peace: Mediating Violent, Ethnic, Intra-State Crises in Africa." Mimeo.

Ramsay, Kristopher W. 2004. "Politics at the Water's Edge: Crisis Bargaining and Electoral Competition." Journal of Conflict Resolution 48(3):459-486.

Rauchhaus, Robert. 2006. "Asymmetric Information, Mediation, and Conflict Management." World Politics 58(2):207-401.

Regan, Patrick \& Aysegul Aydin. 2006. "Diplomacy and other forms of intervention in civil wars." Journal of Conflict Resolution 50(5):736-756.

Sartori, Anne E. 2002. "The Might of the Pen: A Reputational Theory of Communication in International Disputes." International Organization 56(1).

Satterthwaite, Mark A. \& Steven R. Williams. 1989. "Bilateral trade with the sealed bid $k$-double auction: Existence and efficiency." Journal of Economic Theory 48(1):107-133.

Savun, Burcu. 2008. "Information, Bias, and Mediation Success." International Studies Quarterly 52(1):25-47. 
Sherman, Frank L. 1994. "SHERFACS: a cross-paradigm. hierarchical, and contextually sensitive conflict dataset." International Interactions 20(1-2):79-100.

Sherman, Frank L. 2000. "SHERFACS: a cross-paradigm. hierarchical, and contextually sensitive conflict dataset." Computer file ICPSR02292-v12:Last update 2006-10-18.

Skjelsbaek, Kjell. 1986. "Peaceful Settlements of Disputes by the United NAtions and Other Intergovernmental Bodies." Cooperation and Conflict 21(3):139-154.

Smith, Alastair. 1995. "Alliance Formation and War." International Studies Quarterly 39(4):405-25.

Smith, Alastair. 1998. "International Crises and Domestic Politics." American Political Science Review 92(3):623-638.

Smith, Alastair \& Allan Stam. 2003. "Mediation and peacekeeping in a random walk model of civil and interstate war." International Studies Review 5(4):115-135.

Touval, Saadia \& William Zartman. 1985. Introduction: Mediation in Theory. In International Mediation in Theory and Practice, ed. Saadia Touval \& William Zartman. Boulder, CO: Westview Press.

Wilkenfeld, Jonathan, Kathleen Young, Victor Asal \& David Quinn. 2003. "Mediating international crises: Cross-national and experimental perspectives." Journal of Conflict Resolution 47(3):279-301. 